\title{
Designing a Branding Model for Providing Healthcare Services in Iran
}

\author{
Masoomeh Abdi Talarposhti ${ }^{1}$, Ghahraman Mahmoudi2, ${ }^{2 *}$ and Mohammad Ali Jahani ${ }^{3}$ \\ ${ }^{1} \mathrm{PhD}$ candidate of Medical \& Health Services Administration, Sari Branch, Islamic Azad University, Sari, Iran \\ ${ }^{2}$ Hospital Administration Research Center, Sari Branch, Islamic Azad University, Sari, Iran \\ ${ }^{3}$ Social Determinants of Health Research Center, Health Research Institute, Babol University of Medical Sciences, Babol, Iran
}

* Corresponding author: Ghahraman Mahmoudi, Hospital Administration Research Center, Sari Branch, Islamic Azad University, Sari, Iran. Email: ghahraman.mahmoodi@gmail.com

Received 2021 July 09; Revised 2021 September 27; Accepted 2021 October 10.

\begin{abstract}
Background: Branding in the field of healthcare services leads to transparency and utility in the type of services, differentiation of services in the minds of patients and their trust in health centers.

Objectives: Therefore, the present study was conducted to provide a branding model in the field of healthcare services.

Methods: We used a mixed method approach to develop a branding model for providing healthcare services. The study population for qualitative phase included 20 academic and organizational experts using snowball sampling and Delphi technique. For quantitative phase, 830 people referred to health centers were selected as service recipients and 415 medical staff were selected as health care providers. The validity of the questionnaire was confirmed by face, content, and structural validity and its reliability was confirmed by Cronbach's alpha of 0.96 . Quantitative data were presented by EQS software version 6.1 with confirmatory factor analysis (CFA) and using structural equations.

Results: The results of factor structure and measurement equivalence the branding of healthcare services with six main themes of competitive position, brand equity, brand accessibility, brand consolidation in the minds of clients and the market, branding strategies, and consumer-brand relationship in healthcare services branding with 19 sub-themes for clients and providers (CFI= 0.9, TLI=0.8, RMSEA $=0.085$, SRMR $=0.049)$ had a good fit and the internal consistency of the items had significant levels $(\mathrm{P}-\mathrm{value}<0 / 05)$.

Conclusion: According to the research results, the six main themes of competitive position, brand equity, brand accessibility, brand consolidation in the minds of clients and the market, branding strategies, and consumer-brand relationship with 19 sub- themes can be used in the field of health services branding.
\end{abstract}

Keywords: Branding, Health services, Patients, Service providers

\section{Background}

The unpredictable business environment in the present era is associated with the challenges of global competition, technology advancement, and economic growth. Many organizations seek to attract the attention and opinion of their customers, and the path to achieve this goal is through differentiating the brand (1). Branding in the field of healthcare creates trust in intangible products and the possibility of purchasing services from healthcare centers and leads to customer loyalty (2), and promotes brand equity if the brand is used properly and effectively as a tool in healthcare centers (3), so that we can reach the main and fundamental goal, which is improvement in health and quality of life (3). Many health centers are out of competition after a while due to lack of knowledge of marketing science and not taking branding subjects seriously (4). One of the problems of the healthcare system is insufficient information of patients about how to receive services from providers. Thus, effective branding for healthcare services leads to transparency in the type and utility of services, processes, consequently, positive experience of patients about the brand, differentiates services in patients' minds, increases their trust in healthcare centers (5) Although creating a brand image for healthcare providers is currently a novel idea and is receiving less attention, it seems that this idea will become more popular in the upcoming years due to the increasing competition in the health industry. In this regard, it seems that healthcare providers can increase their market share and ensure their profitability by creating personal identity through brand image (1). Since the branding of healthcare services is different, especially in healthcare centers and hospitals (6), and due to the importance of branding management and related value extraction, healthcare services provided by organizations should be guided towards direct branding initiatives with direct perseverance (5). Branding in medical \& healthcare services is an emerging phenomenon that provides several services to its customers and plays an important role in the quality of services for someone in need of healthcare (7). Researchers believe that choosing a brand name for a product can alter consumer judgment about the product and the decision-making process of their purchase (8). The brand in the pharmaceutical industry cannot work against the consumer's desire for a lower price. The consumer may opt for a lower price and show low brand loyalty. In fact, sensitivity to price 
can prevent you from buying drugs with an expensive brand; especially if there is a major difference between the generic drug and the brand (9). Studies have shown that healthcare branding uses marketing principles to promote and create behavior change in society in a good way (3). In this regard, the results of the study of Baştug $S$ et al. showed that for branding, place and geographical location play a significant role in brand image (10) and the findings of Dumont $G$ et al. consider branding as a purely social method in which stakeholders provide three types of material, informational and symbolic resources to establish the brand (11). Teika Odoom et al. also introduced four dimensions of healthcare branding, including brand elements, tangibles, medical quality of staff and type of healthcare services effective in brand promotion (7). Therefore, building strong brands is one of the priorities of many organizations, because strong brands can add to the competitive advantage (8), lead to the development of strategies to improve quality for health organizations (9) and create an emotional connection between the staff and clients (12).The market system of health services in Iran is rapidly moving towards competitiveness and organizations cannot survive in such competitive conditions unless they identify the overt, covert, immediate and future needs and demands of different clients and people who require healthcare services using specific marketing tools before any sort of establishment, transformation and development of activities. Furthermore, they have to determine and define their target market and understand the situation of competitors and the environmental conditions governing society and the health system, and gather necessary and sufficient information. They need to improve their revenue and profits through marketing methods and mixed elements of service marketing, market share, customer share, and have a stable and dynamic presence in the market with the help of reputation, prestige and position they create in the minds of their audiences (13).

\section{Objectives}

In this study, we seek to design a branding framework in the field of healthcare services based on a mixed method approach by which healthcare centers can improve the quality of healthcare services through branding and patients can have the right to choose the best service centers.

\section{Methods}

\subsection{Study design}

This study was conducted using a mixed method approach in two main quantitative and qualitative phases in Iran. This research can be considered a field research whose time domain was from April 2020 to March 2021.

\subsection{Qualitative phase}

This research was conducted in several steps. Step 1: Reviewing the texts by searching library resources: In this step, in order to gain information and knowledge about the subject, database searching was done in the following databases: OVID, CINAHL, SCOPUS, PubMed, Google Scholar, Magiran, Iran doc, SID, Science direct using the keywords "Healthcare Services","Branding", "Brand", "Healthcare Service Branding" and "Service Branding". After identifying the initial dimensions by reviewing the texts, the proposed initial theoretical model was presented in a meta-synthesis form in a semi-open questionnaire to receive the opinions of expert. In the second step Based on Delphi approach, a semi-structured (semiopen) questionnaire was presented to 20 experts in the field of content and measurement of health services to collect the opinions of experts. In addition to special education in the field of healthcare services, the experts had organizational work experience. In order to increase the reproducibility of the comments, four rounds of Delphi technique were considered so that the dimensions of the determined model would have the least variation. At this step, a final version of the questionnaire was prepared by presenting a structural model to be evaluated for implementation in the quantitative stage. In the third step: A copy of the questionnaire prepared from the previous step was presented to the clients and the health care providers.

To select the experts, the snowball sampling method (first targeted then networking) was used. In collecting information from experts, Delphi technique was used, and based on the opinions of experts, six main themes (competitive position, brand equity, brand accessibility, brand consolidation in the minds of clients and the market, branding strategies, and consumer-brand relationship) and 19 sub-themes (optimal design, advertisement, innovation, diversity, customer loyalty, performance and efficiency, reputation and existing beliefs, justice in access, physical access, social investment, competitive advantage, individual and ethical competence of providers, communication skills of providers, training providers, performance evaluation, provider flexibility, resource provision, patient's rights charter, and satisfaction survey) were presented. The initial theoretical model was proposed in the form of metacombination based on a semi-structured questionnaire of 109 items to get expert opinions using the Delphi technique in four rounds. The questionnaire was sent in person and by email. The first round of Delphi technique included 109 items in terms of importance (1-10) and relevance, the second round 92 items, the third round 85 items and the fourth round 83 items, including the optimal design 
(questions 1-6), advertisement (questions 7-11), innovation (questions 12-14), diversity (questions 15-18), customer loyalty (questions 19-21), performance and efficiency (questions 22-25), reputation and existing beliefs (questions 26-33), justice in access (questions 34-36), physical access (questions 37-39), social investment (questions 4043), competitive advantage (questions 44-52), individual and ethical competence of providers (questions 53-57), communication skills of providers (questions 58-61), training providers (questions 6265), performance evaluation (questions 66-69), provider flexibility (questions 70-73), resource provision (questions 74-76), patient's rights charter (questions 77-80), and satisfaction survey (questions 81-83). Using Delphi technique, the questions of the questionnaire reached saturation stage with 83 questions in the fourth round and they were examined based on the Delphi technique after the fourth round and reaching a consensus based on Kendall rank correlation coefficient.

\subsection{Inclusion and exclusion criteria in qualitative phase}

Inclusion criteria in the qualitative phase were having a specialized doctoral degree, general practitioner or specialist and having at least 5 years of experience in healthcare organizations. Exclusion criteria were having less than 5 years of work experience, not having a specialized doctoral degree, general practitioner or higher, not having a history of administrative activity and also lack of desire and satisfaction to participate in the research.

To evaluate face validity, a quantitative questionnaire was provided to the patients and health care providers to see if the perception of the client and the provider about the items is the same as the researcher's perception of the items and each question of the questionnaire was evaluated in terms of importance in a 5-point Likert scale: very high (5 points for 8-10 importance), high (4 points for 6-8 importance), medium (3 points for 4-6 importance), low (2 points for 2-4 importance), and very low (1 point for 1-2 importance). After completing the questionnaires, the score of each question was calculated using the effect size of each item.

To evaluate the content validity in a quantitative way, content validity coefficient and content validity index were used. In this method, the questions were provided to the experts and they were asked to determine how much the questions covered the target areas, and how well they can assess the content of the questionnaire. If there is agreement between different people on the content validity of the questionnaire, that question has content validity. Therefore, in order to check the validity of the qualitative content, a questionnaire (manually or electronically) was given to five experts with at least five years of work experience and their opinions were obtained.

In order to evaluate the validity of quantitative content and to ensure that the most correct and important content (necessity of the question) has been selected, the content validity ratio (CVR) was used. For this purpose, the questionnaire was provided to the panel of experts and they were asked to evaluate each of the questions in terms of necessity criteria in three categories: "necessary", "not necessary but useful" and "not necessary". It should be noted that according to the number of expert panels, the minimum acceptable value of CVR for this study was 0.69 .

To evaluate the theoretical model of branding model, confirmatory factor analysis and internal consistency were used as the reliability of the questionnaire based on Cronbach's alpha.

\subsection{Inclusion and exclusion criteria in quantitative phase}

In the quantitative part, the inclusion criteria for health care providers or experts were employment in health centers affiliated to the country's medical universities, having at least five years of experience in health centers, and willingness and satisfaction to participate in the research. Inclusion criteria for healthcare services clients were clients from centers affiliated to medical universities of the country with at least high school diploma, willingness and satisfaction to participate in the research, and urban centers.

The exclusion criteria for healthcare providers or experts were unwillingness to participate in research, transfer from healthcare centers to hospitals affiliated to medical universities, and rural centers. Exclusion criteria for health care clients were education less than high school diploma, the elderly and those with physical and mental disabilities, unwillingness to participate in the research as well as rural centers.

\subsection{Data Collection and Sampling}

The study population in the quantitative phase included two groups of patients referring to government healthcare centers of Iran as service recipients and the staff of government healthcare centers as service providers. The sampling was based on cluster sampling. To determine the total sample size, the country was divided into five regions (north, south, center, east and west) based on cluster sampling. To determine the sample size of service providers and clients, the number of questions was multiplied by 5 and 10 , respectively; since the questionnaire included 83 questions, the sample size of service providers was determined to be 415 $(83 \times 5)$ and the sample size of clients was 830 $(83 \times 10)(14)$. Samples participated in the study voluntarily and were assured that the information about their answers would remain confidential. The 
use of random samples for tool-making and theory testing can increase the generalizability of the results. Therefore, in the present study, an attempt was made to approach this goal by considering a multi-stage sampling framework. For sampling, the country was first divided into five regions (north, south, center, east and west). Then in each of these regions, six areas were considered in the central region (south of Tehran, Karaj, Qazvin, Damavand, Kashan, Isfahan), in the northern region (Ghaemshahr, Sari, Amol, Gorgan, Semnan, Golestan), in the southern region (Yasuj, Khorramshahr, Abadan, Shiraz, Bandar Abbas, Kish), in the eastern region (Mashhad, Neishabour, Bojnourd, Quchan, Kashmar, Kerman), and in the western region (Kermanshah, Hamedan, Sanandaj, Tabriz, Lorestan, Ardabil) and in each of the areas, one healthcare center was randomly selected based on the list of health centers throughout the country. On average, about 28 patients were considered in each healthcare center, and the share of each region was as follows: 166 people in the center, 166 people in the north, 166 people in the south, 166 people in the east, and 166 people in the west. About 14 people were considered as provides, and the share of each region was as follows: 83 people in the center, 83 people in the north, 83 people in the south, 83 people in the east, and 83 people in the west). After obtaining the necessary permits in the quantitative stage, the researcher referred to the target healthcare centers and explained the purpose of the research to the clients and providers, and after obtaining their informed consent and strict observance of inclusion and exclusion criteria, the questionnaires were given to them. Questionnaires were completed in person and by e-mail in the mentioned regions. It is noteworthy that more questionnaires were distributed due to possible drop; out of 1300 completed questionnaires, 1245 questionnaires were finally entered into the software and analyzed.

In addition to the questions in the main section, the subject's demographic information including age, gender, occupation, work experience, level of education, field of study, place of residence and name of healthcare centers were also assessed. In Table 1, the number and count of items related to each dimension is specified in the research questionnaire.

\begin{tabular}{|c|c|c|c|}
\hline Row & Model dimensions & Item count & Item number \\
\hline 1 & Competitive position & 14 & $1-14$ \\
\hline 2 & Brand equity & 19 & $15-33$ \\
\hline 3 & Brand accessibility & 10 & $34-43$ \\
\hline 4 & Brand consolidation in the minds of clients and the market & 18 & $44-61$ \\
\hline 5 & Branding strategies & 15 & $62-76$ \\
\hline 6 & Consumer-brand relationship & 7 & $77-83$ \\
\hline 7 & Total questionnaire & 83 & $1-83$ \\
\hline
\end{tabular}

\subsection{Data analysis}

Evaluation of the items related to each of the dimensions was based on 5-point Likert scale (strongly disagree (1), disagree (2), neutral (3), agree (4), strongly agree (5)). Quantitative phase analysis (confirmatory factor analysis) was performed using EQS version 6.1. However, MPLUS version 7.4 was used to analyze measurement invariance.

\section{Results}

According to the research findings, $50 \%$ of the experts in the qualitative phase were men, $35 \%$ of the respondents were aged 45 to 49 years, $75 \%$ of the experts had 5 to 15 years of work experience and $85 \%$ of them had a specialized doctoral degree. In the quantitative phase, $63 \%$ of the clients were women, $48 \%$ of the respondents were 28 to 39 years old, $32 \%$ of the clients with zero to 7 years of work experience, and $61.3 \%$ of the clients had a bachelor's degree. In the case of service providers, $51 \%$ were women, $39 \%$ were 36 to 43 years of age, $32 \%$ of service providers had 5 to 10 years of work experience and $55 \%$ of respondents had a bachelor's degree (Table 2).

\begin{tabular}{|c|c|c|c|c|c|c|}
\hline Variables & $\begin{array}{c}\text { Frequency and } \\
\text { percentage of } \\
\text { experts }\end{array}$ & $\begin{array}{l}\text { Cumulative } \\
\text { percentage } \\
\text { of experts }\end{array}$ & $\begin{array}{c}\text { Frequency and } \\
\text { percentage of } \\
\text { clients }\end{array}$ & $\begin{array}{l}\text { Cumulative } \\
\text { percentage of } \\
\text { clients }\end{array}$ & $\begin{array}{c}\text { Frequency and } \\
\text { percentage of } \\
\text { providers }\end{array}$ & $\begin{array}{c}\text { Cumulative } \\
\text { percentage of } \\
\text { providers } \\
\end{array}$ \\
\hline Gender & $\begin{array}{l}10(50 \%) \text { men \& } \\
10(50 \%) \text { women }\end{array}$ & $50 \%$ & $306(63 \%)$ women & $63 \%$ & 211 (51\%) women & $51 \%$ \\
\hline Age & $\begin{array}{c}45-49 \text { years } \\
7(35 \%)\end{array}$ & $65 \%$ & $\begin{array}{c}28-39 \text { years } \\
399(48 \%)\end{array}$ & $51 \%$ & $36-43$ years & $66 \%$ \\
\hline Job & $\begin{array}{c}\text { Faculty member } \\
15(75 \%)\end{array}$ & $90 \%$ & $\begin{array}{l}\text { Employees of other } \\
\text { departments } \\
327(39 \%)\end{array}$ & $59 \%$ & $\begin{array}{l}\text { Health staff } \\
415(100 \%)\end{array}$ & $100 \%$ \\
\hline $\begin{array}{l}\text { work } \\
\text { experience }\end{array}$ & $\begin{array}{c}\text { 5-15 years } \\
9(45 \%)\end{array}$ & $45 \%$ & $\begin{array}{l}0-70 \text { years } \\
268(32 \%)\end{array}$ & $32 \%$ & $\begin{array}{l}5-10 \text { years } \\
131(32 \%)\end{array}$ & $32 \%$ \\
\hline Education & $\begin{array}{c}\text { specialized } \\
\text { doctoral degree } \\
17(85 \%)\end{array}$ & $95 \%$ & $\begin{array}{c}\text { bachelor's degree } \\
509(61 \%)\end{array}$ & $72 \%$ & $\begin{array}{c}\text { bachelor's degree } \\
230(55 \%)\end{array}$ & $56 \%$ \\
\hline
\end{tabular}




\begin{tabular}{|c|c|}
\hline Main themes & Sub-themes \\
\hline Competitive position & $\begin{array}{l}\text { Optimal design } \\
\text { Advertisement } \\
\text { Innovation }\end{array}$ \\
\hline Brand equity & $\begin{array}{c}\text { Variety } \\
\text { Loyalty to clients } \\
\text { Performance and efficiency } \\
\text { Existing images and beliefs }\end{array}$ \\
\hline Brand accessibility & $\begin{array}{c}\text { Justice in access } \\
\text { Physical access } \\
\text { Social investment }\end{array}$ \\
\hline Brand consolidation in the minds of clients and the market & $\begin{array}{l}\text { Competitive Advantage } \\
\text { Individual and ethical competence of providers } \\
\text { Providers' communication skills }\end{array}$ \\
\hline Branding strategies & $\begin{array}{c}\text { Training to providers } \\
\text { Performance evaluation } \\
\text { Provider flexibility } \\
\text { Providing resources }\end{array}$ \\
\hline Consumer-brand relationship & $\begin{array}{c}\text { Patient's rights charter } \\
\text { Satisfaction Survey }\end{array}$ \\
\hline
\end{tabular}

Table 4. 6-Factor fit indices of healthcare services branding from the perspective of clients

\begin{tabular}{|c|c|c|c|c|c|c|c|c|}
\hline Variable & $\chi^{2}$ & Df & CFI & IFI & TLI & RMSEA(90\% CI) & SRMR & $\begin{array}{c}\text { Cronbach's } \\
\text { alpha }\end{array}$ \\
\hline Competitive position & 482.7 & 74 & 0.9 & 0.9 & 0.9 & $0.08(0.07,0.09)$ & 0.05 & 0.91 \\
\hline Brand equity & 1181.44 & 146 & 0.8 & 0.8 & 0.8 & $0.09(0.088,0.097)$ & 0.06 & 0.94 \\
\hline Brand accessibility & 246.59 & 32 & 0.9 & 0.9 & 0.9 & $0.09(0.08-, 0.10)$ & 0.053 & 0.88 \\
\hline $\begin{array}{l}\text { Brand consolidation in the minds of clients and the } \\
\text { market }\end{array}$ & 841.3 & 132 & 0.9 & 0.9 & 0.8 & $0.08(0.075,0.086)$ & 0.054 & 0.94 \\
\hline Branding strategies & 790.881 & 84 & 0.9 & 0.9 & 0.8 & $0.101(0.094,0.107)$ & 0.053 & 0.95 \\
\hline Cnsumer-brand relationship & 89.26 & 13 & 0.96 & 0.96 & 0.9 & $0.084(0.068,0.101)$ & 0.034 & 0.91 \\
\hline Healthcare services branding with 6 factors & 1216.25 & 145 & 0.9 & 0.9 & 0.8 & $0.094(0.089,0.099)$ & 0.049 & 0.96 \\
\hline
\end{tabular}

The findings of this hybrid research were the result of reviewing texts, Delphi technique in the qualitative phase and also a quantitative phase conducted on 830 people referring to healthcare centers and 415 healthcare providers, and this study includes six main variables with 19 sub-themes in the branding model in different areas of healthcare services, which is shown below (Table 3).

Confirmatory factor analysis has provided an acceptable fit in evaluating the proposed theoretical model. As shown in Table 4 (from the perspective of clients), Table 5 (from the perspective of service providers) and Table 6 (clients and providers), all fit indices are within the acceptance range, and the Cronbach's alpha value of the model (clients, providers, and total) indicates the high internal consistency of the items (Tables 4, 5, 6). Figure 1 also shows the factor loads of each item whose values are above 0.4 (Figure 1).

According to Table 7, the measurement invariance for 6-factor fit model was determined by comparing changes in the comparative fit indices $(\triangle \mathrm{CFI})$ and root-mean-square error of approximation $(\triangle \mathrm{RMSEA})$ between models with increasing constraints. A change of less than or equal to 0.01 for CFI and less than or equal to 0.05 for RMSEA are considered as invariance. In addition, although the $\chi 2$ statistic is strongly dependent on the sample size, the $\Delta \chi^{2}$ is considered for interpreting the fit of nested models. The non-significant P-value of $\Delta \chi^{2}$ is considered as invariance. A minimal change in fit model for each succeeding model, shown by the change in RMSEA and CFI between the six models, supported measurement invariance (e.g., RMSEA baseline RMSEA constrained $=\Delta$ RMSEA; $\triangle$ RMSEA $<0.05$ and CFI baseline - CFI constrained $=\Delta \mathrm{CFI} ; \Delta \mathrm{CFI}<0.01$ supported metric/scalar invariance). Results show that this questionnaire is suitable for the client and the provider for 6 -factor model at configural, metric, and scalar levels (13).

\begin{tabular}{|c|c|c|c|c|c|c|c|c|}
\hline Variable & $\chi^{2}$ & Df & CFI & IFI & TLI & RMSEA(90\% CI) & SRMR & Cronbach's alpha \\
\hline Competitive position & 234.14 & 74 & 0.9 & 0.9 & 0.9 & $0.08(0.07,0.09)$ & 0.05 & 0.91 \\
\hline Brand equity & 583.47 & 146 & 0.8 & 0.8 & 0.8 & $0.08(0.07,0.09)$ & 0.06 & 0.93 \\
\hline Brand accessibility & 129.71 & 32 & 0.9 & 0.9 & 0.9 & $0.08(0.07,0.1)$ & 0.055 & 0.88 \\
\hline $\begin{array}{l}\text { Brand consolidation in the minds of clients } \\
\text { and the market }\end{array}$ & 361.53 & 132 & 0.9 & 0.9 & 0.8 & $0.065(0.057,0.073)$ & 0.049 & 0.93 \\
\hline Branding strategies & 413.77 & 84 & 0.9 & 0.9 & 0.8 & $0.097(0.088,0.107)$ & 0.06 & 0.95 \\
\hline Consumer-brand relationship & 56.44 & 13 & 0.95 & 0.95 & 0.9 & $0.09(0.067,0.114)$ & 0.04 & 0.91 \\
\hline Healthcare services branding with 6 factors & 576.27 & 145 & 0.9 & 0.9 & 0.8 & $0.085(0.077,0.092)$ & 0.056 & 0.95 \\
\hline
\end{tabular}




\begin{tabular}{llccccccc}
\hline \multicolumn{1}{l}{ Table 6. 6-Factor fit indices of healthcare services branding (clients and providers) } \\
\hline Variable & $\chi^{\mathbf{2}}$ & Df & CFI & IFI & TLI & RMSEA(90\% CI) & SRMR & Cronbach's alpha \\
\hline $\begin{array}{l}\text { 6-factor fit indices of health care service } \\
\text { branding (clients and providers) }\end{array}$ & 1939.66 & 146 & 0.9 & 0.9 & 0.8 & $0.085(0.08,0.09)$ & 0.049 & 0.96 \\
\hline
\end{tabular}

\begin{tabular}{|c|c|c|c|c|c|c|c|c|c|c|}
\hline Model & N-Parameters & $\chi^{2}$ & df & $\Delta \chi^{2}$ & df & p-value & RMSEA & $\triangle$ RMSEA & CFI & $\Delta \mathrm{CFI}$ \\
\hline Configural & 144 & 1701.28 & 274 & & & & 0.091 & & 0.907 & \\
\hline Metric & 131 & 1706.68 & 287 & $\mathrm{n} / \mathrm{a}^{*}$ & & & 0.089 & 0.002 & 0.907 & 0 \\
\hline Scalar & 118 & 1736.37 & 300 & 11.27 & 13 & 0.587 & 0.088 & 0.001 & 0.906 & 0.001 \\
\hline
\end{tabular}

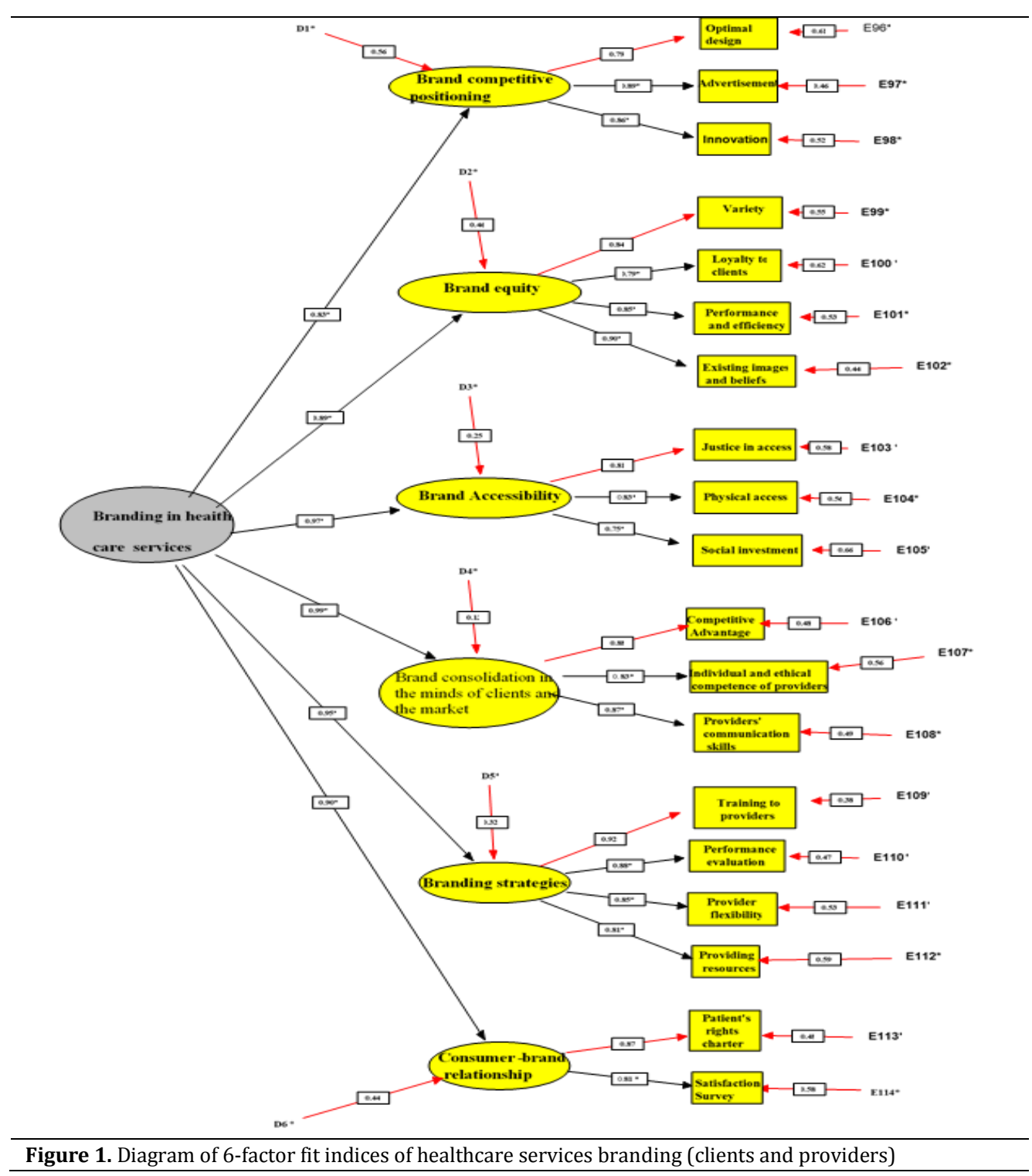

\section{Discussion}

The results of this study showed that six main themes and 19 sub-themes were involved in designing the branding model for healthcare services. The theme of competitive position has three subthemes: optimal design, advertisement, innovation; the brand equity theme includes four sub-themes: diversity, customer loyalty, performance and efficiency, reputation and existing beliefs; the theme of brand accessibility consists of three sub-themes: justice in access, physical access, social investment; the theme of brand consolidation in the minds of clients and the market includes three sub-themes: competitive advantage, individual and ethical competence of providers, communication skills of providers; the theme of branding strategies includes four sub-themes: training providers, performance evaluation, provider flexibility, resource provision; the theme of consumer-brand relationship includes 
two sub-themes: patient's rights charter, satisfaction survey.

The results showed that the theme of brand's competitive position with the sub-themes of optimal design, advertainment, and innovation has an effective role in the branding pattern of healthcare services. Results of some studies such as Baştuğ et al. entitled "An application of brand personality dimensions to container ports: a place branding perspective" (10); Skaalsvik et al. entitled "Service branding: the development of a typology of service brands at the corporate level" (15); Kalajian. entitled "Employer brand framework for ICT B2B multinationals case study" (3); Evans et al. "on the systematic review of health branding" (16); Bednarik. "On the differences between pharmaceutical brands" (17). Have confirmed this. However, the findings of Martey et al. "On the impact of celebrities' endorsement on brand positioning on mobile telecommunication users in the Eastern Region of Ghana" (12). Show different conclusions, perhaps because of differences in subjects and organizational culture in explaining this issue, it can be said that competitive positioning is necessary for the success of brands in the competitive market, with its speed and irregularities. Patients may encounter similar services and focus mainly on the costs to be paid. Providing more and better features is not enough to attract patients and increase loyalty, but should go beyond service marketing and focus on branding and positioning.

The results of this study showed that the theme of brand equity with sub-themes of diversity, customer loyalty, performance and efficiency, reputation and beliefs have an effective role in the branding pattern of healthcare services. Results of some studies such as Elrod et al. entitled "Driving brand equity in health services organizations" (4); Coleman et al. entitle "Service brand identity" (13); Ahmad et al. entitled "The impact of social media content marketing towards brand health" (18), Achar et al. entitled "Assessment of brand identity of suchirayu hospital" (19); Skaalsvik "Value-Creating Service Brand" (15); Huang et al. entitled "How brand awareness relates to market outcome, brand equity, and the marketing mix" (20); Chahal et al. entitled "Significant components of service brand equity in healthcare sector" (21); Kim et al. entitled "Brand equity in hospital marketing" (22). Has shown the same issue, but the results of Pralea entitled "Branding in health marketing" shows a different result (23). Therefore, in this regard, marking with an emphasis on creating a positive mentality in health care clients helps them establish themselves strategically for the future and on the other hand, to be able to compete effectively with other competing centers. Therefore, it is necessary for healthcare centers to be aware of the role of their brands in creating a positive mentality in their clients in order to grow and expand their presence in the market, and to examine what aspects of the trademarks strengthen this positive mentality towards the brand.

The results of this study showed that the theme of brand accessibility with the sub-themes of justice in access, physical access, and social investment has an effective role in the branding pattern of healthcare services. The results of the study of Adhikari et al. entitled "New forms of development: branding innovative ideas and bidding for foreign aid in the maternal and child healthcare service" (24); Esch et al. entitled "The brand anchoring effect: a judgment bias resulting from brand awareness and temporary accessibility" (25). Have addressed this issue. According to the results of this study, appropriate and fair distribution of healthcare services in the field of prevention and environmental protection based on the needs of clients is very important in branding of healthcare services and can be possible according to the proportion of the population covered with service providers in healthcare service branding.

The results of this study showed that the theme of brand consolidation in the minds of clients and the market with the sub-themes of competitive advantage, individual and ethical competence of providers, and communication skills of providers has an effective role in the branding model of healthcare services. The results of Chen et al. entitled "The coincidence of private branding and foreign sourcing" (26), Chu et al. entitled "A doctor's name as a brand" (27); Evans et al. entitled "Systematic review of healthcare branding" (16); Kalajian. entitled "Employer brand framework for ICT B2B multinationals case study" (3). Have shown the same issue. Thus, in order to create a positive mentality in the clients, healthcare centers should diversify their healthcare services and provide more frequent intervals of healthcare services to their clients with more variety. Therefore, using marketing and brand specialists, using specialized consultation in the field of health, providing healthcare services with the lowest cost and highest quality, capability (scientific, technical, cultural) of providers, observance of core value (patient-centered) by service providers, the existence of a healthcare service support system, the use of virtual systems and services appropriate to the level of literacy and culture of the region contribute to building a brand that establishes an emotional connection with the client and always remains in the client's mind.

The results of this study showed that the theme of branding strategies with sub-themes of training to providers, performance appraisal, provider flexibility, and resource provision has an effective role in the branding model of healthcare services. The results of Toscano et al. entitled "Hospital branding as a strategy for differentiation" (28); Hotez entitled "Crafting your scientist brand" (29); and Kevin et al. entitled "E-Branding Strategies of Internet 
Companies in the United Kingdom" (30). Has expressed the same issue. In this regard can be allocated through adequate funding for equipment purchases and manpower, providers 'flexibility in specific health services, provider performance appraisals, training courses to improve providers' individual skills. In this regard, it is possible to improve the individual skills of providers by allocating sufficient funds to purchase equipment and hire manpower, enhancing the flexibility of providers in specific healthcare services, evaluating providers' performance and holding training courses.

The results of this study showed that the theme of consumer-brand relationship with the sub-themes of patient's rights charter and satisfaction survey has an effective role in the branding model of healthcare services. The study by Skaalsvik entitled "Service branding" (31). Illustrates this issue. Providing healthcare services in the shortest possible time and free of any ethnical, cultural, religious, disease and gender discrimination, providing health services to groups with special priorities such as children, pregnant women, the elderly, the mentally ill patients, prisoners, the mentally and physically handicapped and unattended people, satisfaction survey of clients to provide timely healthcare services and proper behavior of providers can develop consumer-brand relationship.

\section{Limitations of the study}

One of the limitations of this research is that the social context of Iran is public and governmental and thus, the results cannot be generalized to other organizations and areas of service delivery in the health system.

\section{Conclusion}

Results of the study showed that brand competitive position, brand equity, brand accessibility, brand consolidation in the minds of clients and the market, branding strategies, and consumer-brand relationship have an effective role in branding healthcare services. Therefore, it is suggested that 1- Managers and planners of healthcare centers in the country try to increase and improve trust, quality and innovation in service branding in healthcare centers. With the increase of brand credibility, the number of clients also increases and many clients who use the services also recommend this center to others. 2- Healthcare centers grow and expand their presence in the market and be aware of the role of their trademarks in creating a positive mentality in clients and examine what aspects of these trademarks strengthen this positive mentality towards them. 3- Managers provide more facilities for clients who have more experience in visiting the center, respect them and pay attention to them. 4- Whenever healthcare services move towards the private sector, this current situation can be used in branding of healthcare services.

\section{Acknowledgments}

The authors acknowledge the efforts made by experts and specialists for sharing their experiences and knowledge in the qualitative phase and all patients and health providers for participating in the quantitative phase and the technical support made by the Hospital Administration Research Centre of Islamic Azad University, Sari Branch.

\section{Footnotes}

Authors' contributions: $\mathrm{M}$ A and GH M and MA J were the principal investigators and designed the study. M A searched literature. M A and GH M and MA J supported the interview development. M A collected data and prepared data for qualitative analyses. GH M and MA J supervised data collection. M A and GH M and MA J analyzed data. M A drafted the manuscript and both GH M and MA J supported drafting the manuscript. M A contributed to the implementation of the research. All authors have provided comments and critical revisions to the manuscript. All authors approved the final manuscript prior to submission.

Conflicts of Interest: The authors declare that they have no competing interests.

Abbreviations: CFA Model: Confirmatory Factor Analysis Model; $\chi^{2}$ : Chi-Square goodness of fit; Df: Degrees of freedom; RMSEA: Root mean square error of approximation; SRMR: Root mean square error; CFI: Comparative fit index; IFI: incremental fit index; TLI: Tucker Lewis index

Ethics approval: The study was done after holding the ethical code of IR.IAU.CHALUS.REC.1398.041 from Islamic Azad University. Written informed consent was obtained from all study participants.

Funding/Support: There was no financial support in the design of the study, data collection, analysis and interpretation of results and writing of the manuscript.

Informed Consent: Not applicable.

\section{References}

1. Zhang P MQ. Marketing to Develop the Premier Medical Brand in the Huaihai Economic Zone. Cell Biochem. Biophys. 2015;72:371-4. doi: 10.1007/s12013-014-0470-y. [PubMed: 25543331]

2. Kimpakorn NTG. Service brand equity and employee brand commitment. J. Serv. Mark. 2010;24(5):378- 88. doi: 10.1108/08876041011060486

3. Kalajian.m. Employer Brand Framework for ICT B2B Multinationals Case Study: Ericsson AB. Sweden: Stockholm; 2011.

4. JJ EJF. Driving brand equity in health services organizations: the need for an expanded view of branding. BMC Health Serv. Res. 2018;18 (Suppl 3):924. doi: 10.1186/s12913-018-3679-4. [PubMed]: 3054536. 
5. Chaudhuri AH, Holbrook MB. The chain of effects from brand trust and brand affect to brand brand loyalty. J Mark. 2001;65(2):81-93. doi: 10.1509/jmkg.65.2.81.18255.

6. Sirisha B BMK. Branding of hospitals - through tangible factors by selected hospitals. Excel int. j. multidiscip. manag. stud. 2014;4(3):227-37.

7. Teika Odoom Priscilla NBRO. Healthcare branding: Insights from Africa into health service customers' repeat patronage intentions. Int J Healthc Manag. 2019;14(3):663675. doi: $10.1080 / 20479700.2019 .1688503$

8. Kaynak E GsG, Tatoglu E. An integrative framework Linking brand Associations and brand loyalty in professional Sports. J. Brand. Manag. 2008;15:336-57. doi: 10.1057 /palgrave.bm.2550117

9. Kemp E JRK, Becerra E. Healthcare branding: developing emotionally based consumer brand relationships. J Serv Market. 2014;28(2):126-37. doi: 10.1108/JSM-08-2012-0157

10. Baştuğ Sedat ŞGD, Gulmez Secil. An application of brand personality dimensions to container ports: A place branding perspective. J Transp Geogr. 2020;82. doi: 10.1016/j.jtrangeo. 2019.102552

11. Dumont Guillaume OM. Social dynamics and stakeholder relationships in personal branding. J Bus Res. 2020;106:11828. doi: 10.1016/j.jbusres.2019.09.013

12. Martey EM FJ. The impact of celebrities' endorsement on brand positioning on mobile telecommunication users in the Eastern Region of Ghana. Int. j. educ. res. 2014;2(7):397-412.

13. Coleman D DCL, Christodoulides G. B2B service brand identity: scale development and validation. Ind Market Manag. 2014;40 (7):1063-71. doi: 10.1016/j.indmarman.2011.09.010

14. Tinsley H E A BSD. Handbook of Applied Multivariate Statistics and Mathematical Modeling. Academic Press. 2000.

15. Olsen SHB. Service branding: the development of a typology of service brands at the corporate level. Probl. Perspect. Manag. 2015;13(4):53-62.

16. Evans W D, Blitstein J, Vallone D, Post S, Nielsen w. Systematic review of health branding: growth of a promising practice. Transl Behav Med. 2015;5(1):24-36.doi: 10.1007/s13142-0140272-1 PMID:25729450

17. J B. Does brand differentiate pharmaceuticals? Neuro Enocrinol. Lett. 2005;26(6):635-52. [PubMed: 16380705].

18. Ahmad N S MR, Harris M, Harun M. The Impact of Social Media Content Marketing (SMCM) towards Brand Health. Procedia Economic and Finance. 2016;37:331-6. doi: 10.1016/S2212-
5671(16)30133-2.

19. Achar G NV, Nagendra V. Assessment of Brand Identity of Suchirayu Hospital. Int. J. Appl. Manag. Sci. 2016;2(10):9-13.

20. Rong Huang ES. How brand awareness relates to market outcome, brand equity, and the marketing mix. J. Bus. Res. 2012;65(1):92-9. doi: 10.1007/978-1-4939-0277-4_8

21. M CHB. Significant components of service brand equity in healthcare sector. Int J Health Care Qual Assur. 2012;25(4): 343-62. doi: 10.1108/09526861211221518. [PubMed: 22755484]

22. Kim KH KK, Kim DY, Kim JH, Kang SH. Brand equity in hospital marketing. J Bus Res. 2008;61(1): 75-82. doi: 10.1016/j.jbusres.2006.05.010

23. A P. Branding In Health Marketing. Economic Sciences. 2011;4(53):65-73.

24. Adhikari R SP, Sharma J R, Bahadur Chand. New forms of development: branding innovative ideas and bidding for foreign aid in the maternal and child health service in Nepal. Glob. Health. 2018;14(33):1-12. doi: 10.1186/s12992-0180350-0 . [PubMed: 29587775].

25. Esch F-R SB, Redler J, Tobias Langner. The Brand Anchoring Effect: A Judgment Bias Resulting from Brand Awareness and Temporary Accessibility. Psychol. Mark. 2009;26(4):383-95. doi: 10.1002/mar.20278

26. Chen Shih-Fen S LC-YE. The coincidence of private branding and foreign sourcing: Is there a causality direction? . J Bus Res. 2020;108:268-76. doi: 10.1016/j.jbusres.2019.10.032

27. Chu F-Y, Dai, Y-X., Liu, J-Y., Chen, T-J., Chou, L-F., Hwang, Shn-J. A Doctor's Name as a Brand: A Nationwide Survey on Registered Clinic Names in Taiwan. Int. J. Environ. Res. Public Health. 2018;15(6). doi: 10.3390/ijerph15061134 . [PubMed: 29857574].

28. Toscano A B GL. Hospital Branding as a strategy for differentiation: Does Hospital Branding Leverages Hospital Units in the Portuguese Market? Inês Mendonça. 2018.

29. PJ H. Crafting your scientist brand. PLOS Biol. 2018;16(10). doi: 10.1371/journal.pbio.3000024 . [PubMed: 30289876].

30. Kevin I. N. Ibeh YL, Keith Dinnie. E-branding strategies of internet companies: Some preliminary insights from the UK. J. Brand. Manag. 2005;12(5):355-73. doi: 10.1057/palgrave.bm.2540231.

31. Hugo S. Service Branding: Suggesting and Discussing Four Perspectives Influencing a Value-Creating Service Brand at the Company Level. Probl. Perspect. Manag. 2017;13:53-62. doi: 10.5772/intechopen.69636 